\title{
Relationship between quality of ambient air and respiratory diseases in the Polish population
}

\author{
M. Kowalska \\ Department of Epidemiology, Medical University of Silesia, Poland
}

\begin{abstract}
In Poland, after the political and economic changes in the early 90s, the quality of environment, including quality of ambient air, became one of the national target priorities. We observe significant progress in improving the quality of air, however periodically (especially in the autumn-winter season) concentrations of fine particles were systematically exceeding the approved levels.

The aim of this paper was to present the efforts that have been taken to improve the health status of population living in Silesian voivodeship in the south part of Poland, in terms of respiratory diseases. In order to achieve this goal, we collected results of research conducted in the region, and next we compared own observations with other data.

Obtained results suggest that the population in Poland, especially inhabitants of the south part of the country: Silesian voivodeship and Krakow city, are still exposed to a higher concentration of particulate matter and BaP (particularly in the cold season). Those observation is consistent with data published by European Environment Agency. On the other hand, a lot of evidence confirmed that respiratory disorders, including premature mortality, acute bronchopulmonary infection in children, emergency room visits due to asthma, are related to those exposures. It is hoped that two important laws: the Public Health Act and Anti-smog act (adopted in the current year) will become an ally in activities aimed at improving the health of the population in Poland.

The urgent task of epidemiologists is to provide scientific evidence that will help to take effective improvement action, including educational activities among officials, health workers and the whole community. Only a conscious and well-informed society is willing to accept difficult decisions designed to bear the costs related to risk reduction and improving the quality of the environment. Keywords: ambient air pollution, respiratory diseases, public health.
\end{abstract}




\section{Introduction}

In Poland, after the political and economic changes in the early $90 \mathrm{~s}$, the quality of environment, including quality of ambient air, became one of the national target priorities. We observe significant progress in improving the quality of air, however periodically (especially in the autumn-winter season) concentrations of fine particles were systematically exceeding the approved levels. The major reasons for these situations are the increase of emissions from individual heating stoves and car traffic; both sources are responsible for the phenomenon of 'low emission' [1]. Each year we are faced with public protest against the poorer quality of air and the fear associated with potential loss of life or health deterioration [2]. Simultaneously, current data suggest that prevention and health promotion for chronic respiratory diseases (CRD) is definitely insufficient. In group of serious risk factor of $\mathrm{CRD}$ is exposure to indoor and outdoor air pollution [3]. New legislation in Poland consists of two acts: Act of Public Health [4] and current Environmental Protection Law [5] indicating new opportunities for effective corrective action. Because the prevention of respiratory disorders is largely determined by the state of air quality we have to continue to study in the range of environmental epidemiology.

\section{The aim of study}

The aim of this paper was to present the efforts that have been taken to improve the health status of population living in Silesian voivodeship in the south part of Poland, in terms of respiratory diseases. In order to achieve this goal, results of research conducted in the study region were collected, and then the observations were compared with other data.

\section{Material and methods}

To realize established goals of presented paper, author compared results of multiannual researches conducted in Department of Epidemiology, Medical University of Silesia in Katowice, with other published data. Data concerning health effects were obtained from the official registry of the Central Statistical Office in Warsaw (mortality due to respiratory diseases) and from the National Health Found in Katowice (morbidity or outpatient medical visits due to respiratory disorders). The records were analysed according to the classification scheme of the International Classification of Diseases - 10th edition, in which respiratory diseases are described as codes I00-I99. Data on ambient air quality and meteorology conditions was provided by the State Environmental Agency in Katowice and present 24-hour spatial average concentrations of $\mathrm{PM} 10, \mathrm{SO}_{2}$ and $\mathrm{NO}_{2}$, and additionally daily mean temperature, relative humidity or atmospheric pressure). The relationship between daily mortality and daily concentrations of air pollutants was assessed according to GLM procedure, detailed data and adopted procedures were shown in an earlier publication [6]. Similarly, the temporal variabilities of hospitalization and daily admissions to 
general practitioners due to respiratory diseases was revealed in earlier published papers $[7,8]$.

\section{Results}

Current data obtained from the national air quality monitoring suggest that Polish population, especially inhabitants of south part of the country: Silesian voivodeship and Krakow city, are still exposed to higher concentration of particulate matter and $\mathrm{BaP}$ (especially in the cold season) [9].

Table 1: Basic descriptive data in Silesia region: 24-hour spatial average concentrations of particular pollutants and yearly outpatient medical visits due to chronic respiratory diseases (ICD-10: J40-J47) per adults $19+$ year.

\begin{tabular}{|c|c|c|c|c|c|c|}
\hline & $\begin{array}{l}\text { Year and } \\
\text { season }\end{array}$ & $\begin{array}{c}\mathrm{SO}_{2} \\
\left(\mu \mathrm{g} / \mathrm{m}^{3}\right)\end{array}$ & $\begin{array}{c}\mathrm{NO}_{2} \\
\left(\mu \mathrm{g} / \mathrm{m}^{3}\right)\end{array}$ & $\begin{array}{c}\mathrm{PM}_{10} \\
\left(\mu \mathrm{g} / \mathrm{m}^{3}\right)\end{array}$ & $\begin{array}{c}\text { Temp } \\
\left({ }^{0} \mathrm{C}\right)\end{array}$ & $\begin{array}{c}\mathrm{J} 40-\mathrm{J} 47 \\
\text { per } 10000 \\
\text { inhabitant }\end{array}$ \\
\hline \multirow[t]{5}{*}{2007} & January & 12 & 25 & 25 & 3.6 & \multirow[t]{5}{*}{217.2} \\
\hline & February & 17 & 33 & 46 & 1.8 & \\
\hline & July & 9 & NA & 28 & 19.2 & \\
\hline & August & 9 & 27 & 33 & 19.7 & \\
\hline & Yearly average & 12.9 & 31 & 41 & 10.0 & \\
\hline \multirow[t]{5}{*}{2008} & January & 19 & 29 & 40 & 1.9 & \multirow[t]{5}{*}{219.3} \\
\hline & February & 17 & 27 & 51 & 2.9 & \\
\hline & July & 6 & 14 & NA & 18.7 & \\
\hline & August & 6 & 15 & NA & 17.9 & \\
\hline & Yearly average & 18.1 & 33 & 57 & 9.0 & \\
\hline \multirow[t]{5}{*}{2009} & January & 40 & 42 & 66 & -2.6 & \multirow[t]{5}{*}{225.6} \\
\hline & February & 25 & 31 & NA & -0.8 & \\
\hline & July & 4 & 24 & 27 & 19.4 & \\
\hline & August & 6 & 27 & 31 & 18.6 & \\
\hline & Yearly average & 15 & 30 & 42 & 7.0 & \\
\hline \multirow[t]{5}{*}{2010} & January & 45 & 40 & NA & -6 & \multirow[t]{5}{*}{235.2} \\
\hline & February & 34 & 46 & 88 & -1.2 & \\
\hline & July & 6 & 26 & 35 & 20.4 & \\
\hline & August & 7 & 28 & 34 & 18.1 & \\
\hline & Yearly average & 18.1 & 33 & 57 & 9.0 & \\
\hline
\end{tabular}

Table 1 presents selected environmental data measured in the capital city of Silesia region - Katowice. As we can see, the yearly concentration of basic pollutants doesn't change in years and the highest levels were noted in winter months. Moreover, table shows the number of yearly outpatient medical visits due to chronic respiratory diseases (ICD-10 code: J40-J47) in total population of 
Silesian inhabitants aged 19+ years. As we can observe, the yearly coefficient of outpatients' medical visits still increased, from the value 217.2/10,000 in 2007 to $235.2 / 10,000$ in 2010 . It is worth noting that the highest value of coefficient averaged for the period 2007-2010 concern the central part of the Silesian voivodeship [7]. This interesting observation is difficult to explain based on an epidemiological research descriptive, it can be assumed that observed situation could be result of higher population density and density of traffic and resulting from these facts poorer quality air.

Simultaneously, assessed each year daily mortality due to respiratory diseases in total population and in two separate aged groups of Silesians population is also the highest in the cold season. Figure 1 shows a typical variability of daily mortality according to the season.

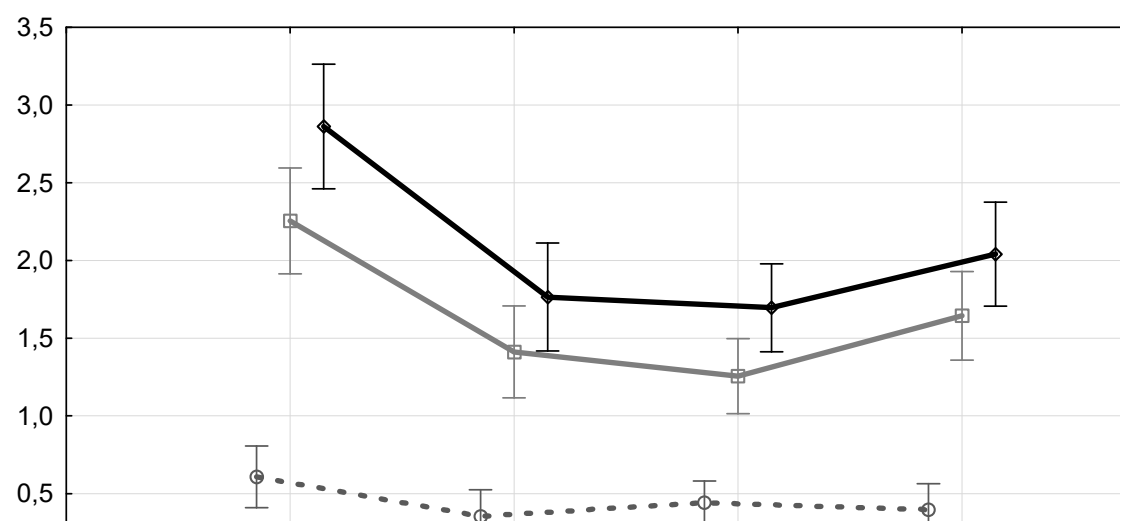

Figure 1: Daily mortality due to respiratory diseases in different age groups of the population inhabiting Silesian voivodeship in the years 2000 2002.

Additionally, we observed close relationship between duration of exposure and the size of health effects. Statistically significant relative risk of respiratory mortality related to an increase of sulphur dioxide and particulate matter (both $\mathrm{PM}_{2.5}$ and $\mathrm{PM}_{10}$ ) concentration by $10 \mu \mathrm{g} / \mathrm{m}^{3}$ was obtained for longer time of exposure, expressed by 5 to even 50-days moving average concentrations (Figure 2). Table 2 presents results of assessment for separate age groups, older inhabitants aged 65 and more and younger than 65 years. As we can observe, the older population is more sensitive to dust contamination (moving average $\mathrm{PM}_{2.5}$ concentration); statistically significant risk of death due to respiratory diseases was noted for all moving average concentrations from 5 to 50 days of exposure. In younger people the significance was noted only for one-two week exposure. 


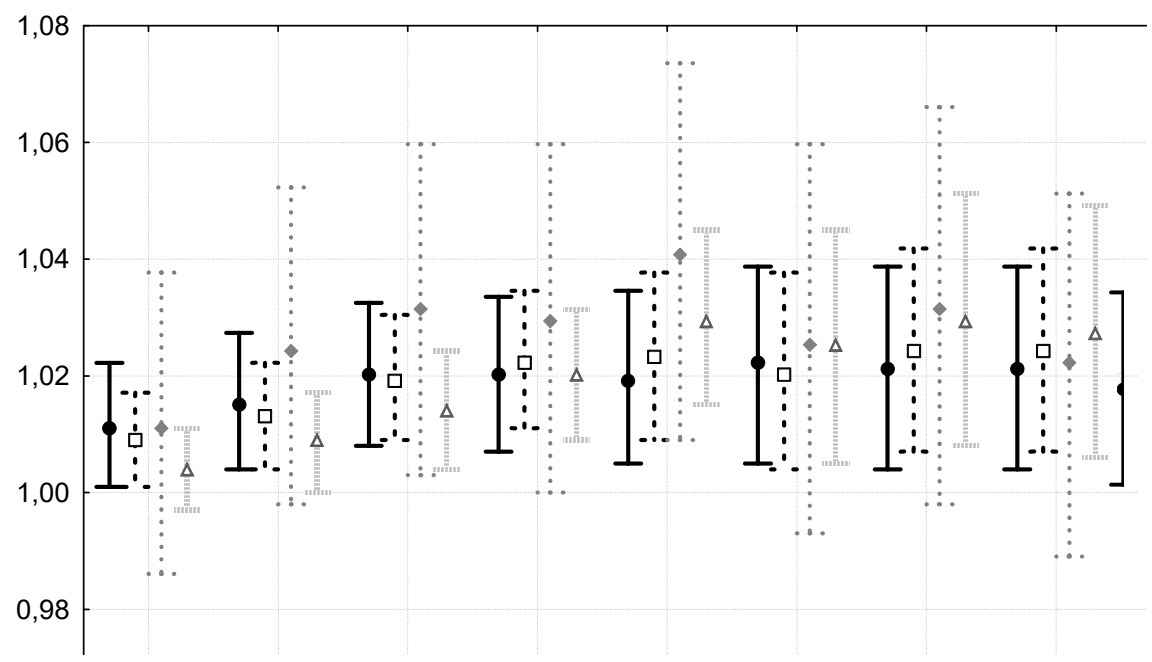

Figure 2: Relative risk of deaths due to respiratory diseases in the total population of Silesian voivodeship in the years 2000-2005.

Table 2: $\quad$ Relative risk of death due to respiratory diseases in two aged groups of inhabitants of Silesia region related to an increase of $\mathrm{PM}_{2.5}$ concentration by $10 \mu \mathrm{g} / \mathrm{m}^{3}, 2000-2005$.

\begin{tabular}{|c|c|c|c|c|}
\hline \multirow{2}{*}{$\begin{array}{l}\text { Period of moving } \\
\text { average } \mathrm{PM}_{2.5} \\
\text { concentration (day) }\end{array}$} & \multicolumn{2}{|c|}{$\begin{array}{c}\text { RR in older population } \\
(65+\text { years })\end{array}$} & $\begin{array}{c}\text { RR in younger population } \\
(<65 \text { years })\end{array}$ \\
\cline { 2 - 5 } & Average & $95 \%$ CI & Average & $95 \%$ CI \\
\hline 1 & 1.001 & $0.991-1.010$ & 1.009 & $0.997-1.021$ \\
\hline 3 & 1.008 & $0.997-1.019$ & 1.009 & $0.995-1.023$ \\
\hline 5 & 1.015 & $1.003-1.028$ & 1.013 & $0.996-1.029$ \\
\hline 7 & 1.021 & $1.006-1.036$ & 1.018 & $1.000-1.037$ \\
\hline 14 & 1.034 & $1.014-1.053$ & 1.024 & $1.000-1.048$ \\
\hline 30 & 1.035 & $1.010-1.061$ & 1.009 & $0.977-1.042$ \\
\hline 40 & 1.039 & $1.012-1.067$ & 1.013 & $0.980-1.048$ \\
\hline 50 & 1.040 & $1.013-1.068$ & 1.007 & $0.973-1.042$ \\
\hline
\end{tabular}

\section{Discussion}

Current monitoring data suggest that inhabitants of southern Poland: Silesian voivodeship and Krakow city are still exposed to a higher concentration of particulate matter and $\mathrm{BaP}$ (particularly in the cold season). That observation is consistent with data published by European Environment Agency which pointed 
that existing concentrations of fine particles are serious hazard to population [10]. Simultaneously, obtained results confirmed a significant relationship between level of exposure to air pollutants and health effect measured as respiratory mortality in population of Silesia region. The impact is stronger in older people, aged 65 and more years, and increases in the cold season each year. On the other hand, many evidences confirmed that respiratory disorders, including premature mortality, acute broncho-pulmonary infection among children, emergency room visits due to asthma, are related with those exposure [11-14]. Recent IARC (International Agency for Research on Cancer) data suggest that fine dust is carcinogenic to human beings [15], respiratory system is acutely sensitive to the damaging effects [16]. Considering the aging of the population and the undiminished hazard, further increase in morbidity and mortality due to chronic respiratory diseases and respiratory cancer can be expected. Results of earlier publication suggest that the reduction of annual mean $\mathrm{PM}_{10}$ by $5 \mu \mathrm{g} / \mathrm{m}^{3}$ would avoid about 6-7 hospitalizations per 100000 inhabitants due to respiratory diseases (ICD-10 code: I00-I99) [17].

The serious problem in Poland is 'low emission' phenomenon which has direct relationship with individual heating and traffic. During each cold season people burn coal in their individual stoves (usually the cheapest one and the low quality) and even simultaneously burning garbage. This situation is a result of poor economic conditions, lack of available alternative sources of clean energy, and the low awareness of environmental health hazards among inhabitants. Therefore, it is important to implement some actions aimed at improving air quality in country, firstly in those regions where the hazard is the highest. It is hoped that two important laws: the Public Health Act and Anti-smog act (adopted in current year) will become an ally in those activities in Poland. The case is quite urgent due to numerous protests of inhabitants of the most polluted regions, e.g. Krakow or Rybnik cities. Certain steps were initiated during the TAB (Take a Breath!) project in Silesia region. Municipality of Sosnowiec city undertook pilot action for tackling air pollution problems. In this activity officials collaborated with representatives of the power grid Tauron and scientists of Medical University of Silesia. Team carried out some training sessions regarding the air pollution sources and the harmful impact on human health. Lectures were addressed mainly to teachers of all schools and kindergartens in the city but also to elderly people (University of Third Age at Silesian University in Sosnowiec), moreover to public officers and city guards or journalists [18]. It is well known, that effective environmental health risk management in developed countries is based on reliable information conveyed to the public and including evidence concerning hazard of ambient air pollution exposure. Further improvement of ambient air quality and consequently the health of the population will not be possible without the cooperation of scientific experts, decision-makers and well informed and educated society [2]. The urgent task of epidemiologists is to provide scientific evidence that will help to take effective corrective action, including educational activities among officials, health workers and the whole community. Only a conscious and well-informed 
society is willing to accept difficult decisions designed to bear the costs related to risk reduction and improving the quality of the environment.

\section{References}

[1] Kowalska, M., \& Zejda, J.E., \& Skrzypek, M. \& et al. Air pollution and daily mortality in urban Katowice, 1994-95 and 2001-02. Polish $J$ Environ Stud, 17(5), pp. 733-38, 2008.

[2] Kowalska M., \& Kowalski M. Join training curricula for capacity building. Teacher's manual. Part II - Health, Central Maining Institute: Katowice, p. 85, 2014 [in Polish].

[3] Bousquet J., \& Khaltaev N. (eds). Global surveillance, prevention and control of Chronic Respiratory Diseases. A comprehensive approach. WHO: Geneva, p. 10, 2007.

[4] Public Health Act. Dz.U.2015 Poz.1916, Warsaw 11.09.2015, Poland Online. www.dziennikustaw.gov.pl/du/2015/1916/D2015000191601 [in Polish].

[5] The Act amending the Act - Environmental Protection Law. Dz.U.2015, Poz. 1593, Warsaw 12.10.2015, Poland. Online. http://dokumenty.rcl.gov.pl/D2015000159301.pdf [in Polish].

[6] Kowalska M., \& Skrzypek M., \& Danso F., \& Kasznia-Kocot J. Relative risk of total and cardiovascular mortality in the elderly as related to shortterm increases of PM2.5 concentrations in ambient air. Pol J Environ Stud, 21(5), pp. 1279-1285, 2012.

[7] Kowalska M., \& Niewiadomska E., \& Zejda J.E. Regional and temporal variations in the number of outpatient medical visits (GP) due to chronic respiratory diseases in Silesian voivodeship. Probl Hig Epidemiol, 94(1), pp. 86-91, 2013 [in Polish].

[8] Kowalska M., \& Niewiadomska E., \& Zejda J.E., \& Rejdak M. Regional and temporal variability of GP consultations due to asthma in children aged 0-18 years in Silesian voivodeship. Przegl Epidemiol, 67, pp. 497501, 2013.

[9] Supreme Audit Office (NIK). Air protection against pollution. Results of control. Warsaw 2014. Online. https://www.nik.gov.pl/plik/ id,7764,vp,9732.pdf [in Polish].

[10] European Environment Agency (EEA). Air quality in Europe - 2014 report. Luxembourg Publications Office of the European Union. Online. http://www.eea.europa.eu/publications/air-quality-in-europe-2014

[11] Pope C.A., \& Dockery D.W. Health effects of fine particulate air pollution: lines that connect. J Air Waste Manag Assoc, 56, pp.709-14, 2006.

[12] Jędrychowski W., \& Perera F., \& Spengler J. \& et al. Intrauterine exposure to fine particulate matter as a risk factor for increased susceptibility to acute broncho-pulmonary infections in early childhood. Int J Hyg Environ Health, 216(4), pp. 395-401, 2013. 
[13] Zheng X.Y., \& Ding H., \& Jiang L.N., \& Chen S.W. Association between Air Pollutants and Asthma Emergency Room Visits and Hospital Admissions in Time Series Studies: A Systematic Review and MetaAnalysis. PLoS One, 10(9), pp. e0138146, 2015.

[14] Samek L. Overall human mortality and morbidity due to exposure to air pollution. IJOMEH, 29(3), 2016. Online. http://dx.doi.org/10.13075/ ijomeh. 1896.00560

[15] International Agency for Research on Cancer (IARC). Outdoor air pollution a leading environmental cause of cancer deaths. Press release 221. Lyon 2013. Online. https://www.iarc.fr/en/media-centre/iarcnews/ pdf/pr221_E.pdf

[16] Hart J.E., Spiegelman D., Beelen R. et al. Long-Term Ambient Residential Traffic-Related Exposures and Measurement Error-Adjusted Risk of Incident Lung Cancer in the Netherlands Cohort Study on Diet and Cancer. Environ Health Perspect, 123, pp. 860-866, 2015.

[17] Kowalski M., \& Kowalska K., \& Kowalska M. Health benefits related to the reduction of PM concentration in ambient air, Silesian voivodeship, Poland. IJOMEH, 29(2), pp. 209-217, 2016.

[18] Take a breath project (TAB project). Trainings on the air pollution. Online. http://www.tabproject.eu/index.php?option=com_content\&view= article \&id=98:trainings-on-the-air-pollution\&catid=10\&Itemid $=107$ 